\title{
AS EQUIPES DIDÁTICAS NA UFMG E A FORMAÇÃO DE DOCENTE DO ENSINO SUPERIOR
}

\author{
UFMG DIDACTIC TEAMS AND THE \\ UNDERGRADUATION LECTURES TRAINING
}

Fabiana de Oliveira Bernardo ${ }^{1}$, Liliane Tibúrcio ${ }^{2}$, Leandro de Paula $^{3}$

${ }^{1}$ Historiadora,

Mestre em Educação.

fabianaoliveira@msn.

com

${ }^{2}$ Pedagoga, Mestre

em Educação.

lilianetiburcio@yahoo. com.br

${ }^{3}$ Historiador

e Pedagogo,

Doutorando em

Educação.

leandroufop204@

yahoo.com.br

\section{RESUMO}

O presente artigo discute o papel das equipes didáticas na formação dos pós-graduandos da UFMG que realizaram o curso de Formação em Docência do Ensino Superior oferecido pelo GIZ - Diretoria de Inovações tecnológicas. Além disso, investiga e relaciona o papel do professor tutor na formação dos pós-graduandos. Foram utilizados dados recolhidos a partir de questionário respondido por esses sujeitos e a conclusão desta analise é que os pós-graduandos que participaram da pesquisa, em geral, consideram a participação em uma equipe didática como importante para sua formação, favorecendo a construção coletiva de conhecimentos e a horizontalidade nas relações professor/orientador e aluno. Consideram, também, que atuar em atividades docentes pode ser dado como um elemento formador positivo e que antecipa situações que ocorrerão em sua trajetória profissional.

Palavras-chave: Equipes Didáticas. Expansão do Ensino Superior e Formação de Docentes do Ensino Superior. 


\section{INTRODUÇÃO}

Em 2007, a Universidade Federal de Minas Gerais (UFMG) elaborou uma proposta com vistas a aderir ao Programa de Apoio a Planos de Reestruturação e Expansão das Universidades Federais (Reuni). Nessa proposta estavam previstas diversas ações com o objetivo de garantir a expansão do ensino superior. Entre essas ações nos interessa, mais especificamente, a constituição de equipes didáticas, que podem ser entendidas como um mecanismo de renovação metodológica do ensino. Essas equipes teriam ainda a finalidade de formação de discentes da pós-graduação interessados em seguir carreira docente, especialmente aquela relacionada ao ensino superior, conforme defendido na proposta da UFMG. ${ }^{1}$

Tendo em vista que os sujeitos, em suas práticas cotidianas, reelaboram e ressignificam aquilo que foi prescrito, pareceunos interessante investigar de que maneira a participação em uma equipe didática incidiu na formação dos estudantes de pós-graduação que tiveram essa experiência. Assim, este artigo tem como objetivo refletir sobre o impacto das equipes didáticas na formação de pós-graduandos que participaram do Curso de Formação em Docência do Ensino Superior, oferecido pelo GIZ - Rede de Desenvolvimento de Práticas de Ensino Superior, vinculado a Pró-Reitoria de Graduação (Prograd). ${ }^{2}$

1 UFMG-REUNI. Universidade Federal de Minas Gerais: REUNI. Disponível em: <http://www.ufmg.br/reuni/>. Acesso em: 31 jan. 2014.

${ }^{2}$ Para uma discussão a respeito da criação do GIZ e das atividades que ele realiza, sugerimos o trabalho de Coelho (2012). 
Foi aplicado, em 2013, um questionário a partir do qual coletamos e analisamos dados que nos ampararam na compreensão de uma série de questionamentos relacionados à formação de docentes para o ensino superior no curso oferecido pelo GIZ. Com o objetivo de responder ao problema deste artigo, selecionamos sujeitos específicos, ou seja, das 273 pessoas que contribuíram com respostas no questionário amplo, elegemos apenas aquelas que participaram do Curso de Formação em Docência do Ensino Superior enquanto eram bolsistas Capes/Reuni, o que perfaz um total de 147 sujeitos.

Para verificar de que maneira as equipes didáticas incidiram na formação dos pós-graduandos, percorremos três caminhos. Primeiramente, apresentamos os principais objetivos das equipes, contidos no projeto elaborado pela UFMG para adesão ao Reuni. Depois, expusemos de que maneira alguns departamentos de ensino organizaram equipes didáticas. Por fim, com base nos dados oferecidos pelos próprios pósgraduandos, discutimos sobre como apreenderam sua atuação como bolsistas Capes/Reuni, considerando suas atividades de docência e os aspectos de formação, previstos na proposta da UFMG.

\section{O REUNI E A PROPOSTA DE ADESÃO ELABORADA PELA UFMG}

O Reuni, instituído pelo Decreto no 6.096, de 24 de abril de 2007, teve como principal objetivo:

Criar condições para a ampliação do acesso e permanência na educação superior, no nível de graduação, para o aumento da qualidade dos cursos 


\begin{abstract}
e pelo melhor aproveitamento da estrutura física e de recursos humanos existentes nas universidades federais, respeitadas as características particulares de cada instituição e estimulada a diversidade do sistema de ensino superior (BRASIL, 2007, p. 10)
\end{abstract}

As Diretrizes Gerais daquele programa indicam que era necessário repensar e reestruturar o ensino superior das universidades federais brasileiras, tanto em seus aspectos acadêmicos quanto curriculares, para o alcance de algumas metas estabelecidas. Entre elas podemos destacar: a elevação da taxa de conclusão média de cursos presenciais para $90 \%$ e a relação de 18 alunos por professor.

Além disso, indicou-se a necessidade de flexibilizar e melhorar a qualidade do ensino superior, nas Diretrizes do Reuni. Tal necessidade guarda relação com o diagnóstico de que, no sistema brasileiro de ensino superior, ocorre certa prevalência de currículos pouco flexíveis, baseados em uma concepção fragmentada do conhecimento; práticas pedagógicas tradicionais, como as aulas expositivas; fosso entre graduação e pós-graduação; ênfase na formação profissional, com lacunas na proposta de uma formação cidadã e altos índices de evasão.

O Reuni propôs um processo de adesão voluntária, em que as universidades federais interessadas deveriam apresentar suas propostas de acordo com as diretrizes do projeto. As propostas aprovadas pelo Ministério da Educação (MEC) teriam sua viabilidade financeira garantida por aquele órgão, mediante termo de pactuação, no período de 2008-2012.

Foram estabelecidas seis dimensões que deveriam ser combinadas nas propostas de adesão elaboradas pelas 
universidades federais. Entre essas dimensões nos interessa aqui aquelas que tangem à questão da formação docente, quais sejam: a Renovação Pedagógica da Educação Superior e o Suporte da Pós-graduação ao Desenvolvimento e Aperfeiçoamento Qualitativo dos Cursos de Graduação. ${ }^{3}$

Em relação à Renovação Pedagógica, as universidades deveriam propor ações que viabilizassem a articulação da educação superior com a educação básica, profissional e tecnológica. Mais ainda, a atualização de metodologias e de tecnologias de ensino-aprendizagem e programas de capacitação pedagógica.

Sobre o Suporte da Pós-graduação ao Desenvolvimento e Aperfeiçoamento Qualitativo dos Cursos de Graduação, o projeto previa a "articulação da graduação com a pósgraduação: Expansão quali-quantitativa da pós-graduação orientada para a renovação pedagógica da educação superior" (BRASIL, 2007, p. 12). Esse item parece guardar relação com o diagnóstico apresentado de que as aulas expositivas ainda eram as principais formas de abordar os conteúdos no ensino universitário brasileiro.

Uma vez que os professores são os principais responsáveis pela formação discente, é plausível que sejam alvo de ações de formação. Assim, é fundamental que os professores universitários e os estudantes de pós-graduação que pretendem seguir carreira docente sejam sujeitos desse processo.

\footnotetext{
3 As outras quatro dimensões comportam: Ampliação da oferta, Reestruturação Acadêmico-Curricular, Mobilidade Intra e InterInstitucional, Compromisso Social da Instituição.
} 
É importante destacar a flexibilidade que as diretrizes do projeto Reuni comportam, o que favoreceu a elaboração de projetos que consideraram demandas locais. Interessanos, então, mostrar como os aspectos da formação desses sujeitos foram tratados no plano apresentado pela UFMG, mais especificamente, ao que se refere ao papel atribuído às equipes didáticas.

Ao investigar o processo de adesão e implantação do Reuni na Universidade Federal de Minas Gerais, Maria de Lourdes Coelho relata que nos primeiros momentos se estruturou um grupo responsável em elaborar e enviar um projeto nos moldes solicitados pelo MEC:

\begin{abstract}
Uma vez que o MEC publicou o Decreto já formatado, afirmando o que é o Reuni, e solicitou projetos às universidades, o Reitor em exercício indicou uma comissão constituída pelos Pró-Reitor de Graduação, Pró-Reitor de Planejamento, Assessora Especial para assuntos da área de Saúde da UFMG, Pró-Reitora adjunta de Graduação da UFMG e pela Assessora da Prograd, além de outros professores que prestaram assessoria direta ao Reitor. Os membros dessa comissão ficaram encarregados de efetivamente redigir o projeto nos moldes que o MEC solicitou e preparar o seu envio (COELHO, 2012, p. 91).
\end{abstract}

A autora afirma que a elaboração da proposta de adesão ao Reuni foi um grande desafio para a UFMG. Esse projeto se deu de forma muito peculiar e com base na ideia de desenvolver novos cursos abertos e flexíveis, cujos professores pudessem trabalhar em equipes. Além disso, havia a noção de que, juntamente à expansão, ocorreria a reestruturação da Universidade. 
Uma das primeiras concepções da equipe formada para a elaboração da proposta de adesão da UFMG ao Reuni, foi que, juntamente com a entrada de recursos para a contratação de professores e a criação de condições materiais, deveria haver reservas para as renovações pedagógicas, com um setor voltado para o desenvolvimento de metodologias de ensino (COELHO, 2012, p.96).

Nesse contexto, formou-se uma equipe que possibilitou a criação do GIZ - Rede de Desenvolvimento de Práticas de Ensino Superior, responsável pelas ações da Diretoria de Inovação e Metodologias do Ensino Superior da Prograd, que possuía como objetivo principal oferecer uma formação pedagógica para os alunos bolsistas de pós-graduação e para os professores.

Com o objetivo de promover a renovação pedagógica propalada no projeto, propôs-se também a participação da pós-graduação da UFMG nesse processo, auxiliando no desenvolvimento qualitativo dos cursos de graduação. Além disso, a expansão desses cursos, viabilizada pelo Reuni, teve o acompanhamento da organização de equipes didáticopedagógicas. Iniciou-se, portanto, um processo de

Organização de equipes, constituídas por professores, bolsistas de pós-doutorado, bolsistas de doutorado e mestrado, para ministrarem as atividades de ensino de graduação. Os professores, em especial os de maior experiência, serão os responsáveis pela condução dessas equipes e pelo desenvolvimento mais geral das disciplinas. Subdivididas em grupos menores, para aulas de discussão, de estudo dirigido, de resolução de problemas e de laboratório, sob a responsabilidade de parte da equipe, as turmas assim compostas propiciarão um acompanhamento mais individualizado dos estudantes. (UFMG-REUNI, p. 11) 
Dessa forma, no contexto do Reuni, as equipes de apoio à docência da UFMG seriam elementos fundamentais para o aprimoramento do ensino. Como mencionado, tais equipes deveriam ser constituídas por professores e bolsistas que ficariam responsáveis em desenvolver atividades junto às disciplinas de graduação. Ou seja, os pós-graduandos bolsistas Capes/Reuni deveriam integrar uma equipe responsável pelo desenvolvimento de diversas atividades, quais sejam:

\begin{abstract}
Atividades relacionadas com disciplinas práticas: essas equipes poderão diversificar o elenco de atividades práticas desenvolvidas, e melhorar a dinâmica dessas atividades. As equipes trabalharão focadas na especificidade de cada disciplina, visando seu contínuo aperfeiçoamento, com a tentativa de envolver e assistir o aluno de graduação de forma mais efetiva no desenvolvimento das atividades;

Em atividades relacionadas com disciplinas teóricas: as equipes terão nesse caso o objetivo de criar condições para um atendimento mais individualizado ao aluno de graduação, permitindo, por exemplo, a sub-divisão de turmas para "aulas de exercícios", a correção em tempo hábil de listas de exercícios, o atendimento individual a alunos, o acompanhamento na execução de trabalhos e o acompanhamento na utilização de material didático complementar. (UFMG-REUNI, p. 31)
\end{abstract}

\title{
OS OBJETIVOS DAS EQUIPES DIDÁTICAS NA UFMG
}

No intuito de compreender as principais propostas e objetivos da criação de equipes didáticas nas unidades de ensino da UFMG, recorremos à análise da documentação existente sobre tais propostas. Foram analisados projetos de elaboração e implementação de equipes didáticas de todas as grandes áreas 
do conhecimento: Ciências Sociais Aplicadas, Ciências Exatas, Ciências Biológicas, Ciências da Saúde, Ciências Humanas e Artes. $^{4}$

Constatamos que o principal objetivo dessas propostas era possibilitar aos pós-graduandos uma preparação para seguir carreira docente no ensino superior, propiciando aos bolsistas um ambiente de reflexão e discussão da prática docente, além do desenvolvimento da capacidade didática de tais alunos, o que se alinha à proposta geral de adesão. Um exemplo que podemos destacar é a proposta da "Equipe de Docência do Ciclo Introdutório de Ciências Humanas" para o ano de 2011. Nesse plano constava como alguns dos objetivos a contribuição na formação docente de sua equipe e o incentivo para a realização de aulas sobre temas pouco explorados nas disciplinas tradicionais. Em outros planejamentos, por exemplo, o elaborado pela "Equipe Didática do curso de Design de Moda" em 2011 e 2012, constatamos a preocupação em habilitar os futuros profissionais no desenvolvimento de um conhecimento prático e produtivo, contribuindo para a construção de espírito empreendedor nos membros da equipe.

Outra justificativa comum a todas as equipes e bastante enfatizada em vários planejamentos de atividades na UFMG é a centralidade de tais equipes na articulação entre a graduação e a pós, o que levaria ao fortalecimento dos laços entre alunos, professores e bolsistas. Tal aproximação poderia ocorrer também pela interação dos alunos de graduação com os projetos desenvolvidos por professores ou com as pesquisas realizadas pelos alunos de pós-graduação.

\footnotetext{
${ }^{4}$ Foram analisados projetos referentes aos anos de 2010, 2011 e 2012.
} 
Além dos objetivos citados, foi identificada, nos planejamentos de algumas equipes didáticas, a intenção de integrar disciplinas distintas, inclusive de cursos diversos, com atividades interdisciplinares. Observamos essa ideia na proposta elaborada pela "Equipe pedagógica do curso de Arquitetura" para o período de 2010-2012; pela "Equipe de Engenharia Ambiental" (2011); pela "Equipe pedagógica de Metodologia do Departamento de Ciência Política" (2010); pela Equipe de Museologia (2011-2012), entre outras. $\mathrm{O}$ intuito dessa proposta era de oferecer aos alunos de graduação a possibilidade de integrar conhecimentos que eram desenvolvidos anteriormente em diferentes disciplinas isoladas.

A elaboração de materiais didáticos apareceu em alguns planejamentos como meta a ser cumprida pelas equipes didáticas. A "Equipe de Docência do Ciclo Introdutório de Ciências Humanas" (2011) estabeleceu como meta a tradução de textos que não estavam disponíveis em português, além de incentivar a elaboração de textos básicos e a oferta de materiais didáticos por parte da equipe. Além desse caso, encontra-se a elaboração de materiais didáticos como objetivo nas equipes do Bacharelado em Ciência do Estado da Faculdade de Direito (2011), Farmácia (2011-2012), Restauração de Bens Culturais (2011) e Matemática (2011). Nessa última equipe estava prevista, por exemplo, a elaboração de listas de exercícios como recurso para facilitar a aprendizagem dos alunos de graduação. A equipe pedagógica do curso de Filosofia (2011) pretendia elaborar estratégias para despertar, nos alunos de graduação, o interesse pela produção e interpretação de textos filosóficos. 
Podemos elencar outras ações previstas para as equipes didáticas como: a reflexão e o estudo acerca dos programas de disciplinas e métodos de ensino para a graduação; o intuito de possibilitar uma otimização das atividades desenvolvidas em laboratórios científicos; a orientação de trabalhos de conclusão de cursos de graduação, etc.

O planejamento pedagógico para a equipe didática do curso de Geografia, no ano de 2011, previa como atividade primordial dos bolsistas Capes/Reuni a oferta de disciplinas optativas, principalmente, para os alunos do curso noturno.

O objetivo geral é o de, com os bolsistas de pósgraduação, integrar num grande eixo norteador, por meio de uma ampla oferta de disciplinas optativas, uma formação para os alunos de Geografia da UFMG, tanto em Geografia Humana, como em Geografia Física, pois se ampliará a oferta de optativas. Tal ampliação de oferta produzirá um efeito muito positivo na vida dos discentes, proporcionandoIhes uma formação mais específica (Planejamento pedagógico para bolsistas do curso de Geografia da Universidade Federal de Minas Gerais 2011).

O argumento contido na citação nos permite verificar uma função para os bolsistas Capes/Reuni que até então não estava prevista no projeto de adesão da UFMG.

Com a análise dos planejamentos desenvolvidos pelas equipes didáticas da UFMG, é possível constatar a diversidade das finalidades e das metas estabelecidas por elas. No entanto, vale ressaltar que um dos focos principais das propostas elaboradas por essas equipes foi a articulação entre a pósgraduação e a graduação, por meio da realização de atividades 
que possibilitassem a preparação dos pós-graduandos para o ingresso na carreira docente de nível superior.

\section{A FORMAÇÃO DOCENTE DOS BOLSISTAS CAPES/ REUNI}

Como foi demonstrado, podemos dizer que o projeto das equipes didáticas foi gestado, inclusive, com o objetivo de proporcionar apoio à formação dos bolsistas Capes/Reuni, amparando a experiência deles em atividades de reflexão da docência no ensino superior e dando suporte à articulação entre a pós-graduação e a graduação.

Contudo, as fontes tendem a apontar a não efetivação de equipes didáticas da forma como o conceito regulamentar prevê. A definição do que deveria compreender uma equipe didática na UFMG é bastante objetiva. Define-se que sua composição deveria ser mista e contar com os professores de maior experiência na condução dessas equipes e no desenvolvimento mais geral das disciplinas. Além disso, as equipes didáticas deveriam amparar a elaboração de novas metodologias de ensino, em consonância com a realidade de uma universidade em expansão.

Dos 147 bolsistas Capes/Reuni que responderam ao questionário, 77 (52,3\%) consideram que fizeram parte de uma equipe didática. Contudo, ao analisarmos os comentários desses sujeitos, podemos inferir que uma grande maioria não participou de uma equipe didática nos moldes previstos, como pode ser verificado a partir do relato a seguir: 
Na verdade a proposta da equipe didática foi elaborada por mim junto à coordenação da pósgraduação. Mas na época eu era a única bolsista REUNI. E como o programa é interdisciplinar houve dificuldade em definir onde eu atuaria. Mas como todo período de adaptação e implementação tem lá suas confusões, foi necessário isso no início para que as coisas pudessem funcionar melhor depois. No momento estou em outro país para o doutorado sanduíche, mas retorno ao Brasil e à equipe novamente no início do ano. ${ }^{5}$

Situação semelhante também foi relatada por outro cursista: "Éramos eu e mais aluna de mestrado, cada um responsável por uma turma. Tudo era decidido entre nos dois e mais o professor tutor". ${ }^{6}$

Os relatos permitem concluir que esses cursistas, ao receberem algum tipo de apoio em suas atividades docentes, consideraram participar de uma equipe didática. Ao confrontar dados contidos no questionário, pudemos constatar que o conceito de equipe didática usado pelos pós-graduandos não corresponde ao conceito apresentado na proposta da UFMG.

Os dados fornecidos demonstram que, efetivamente, apenas 21 (14,3\%) dos 147 respondentes contaram com a supervisão e apoio de uma equipe didática. Ao analisar os discursos que demonstram quais foram as atividades realizadas no interior das equipes didáticas, percebemos que não podemos considerar que houve a efetiva formação de uma equipe didática, nem na sua estrutura nem em seus objetivos. De

\footnotetext{
${ }^{5}$ Cursista 140

${ }^{6}$ Cursista 44.
} 
acordo com um dos respondentes, "a equipe didática, na verdade, era formada apenas por mim e o professor tutor".7 Em outro caso, o respondente afirma que a equipe não teria uma função bem definida, e seu diálogo seria maior com o professor tutor.

Vale destacar que a figura do professor tutor foi enaltecida como imprescindível na formação dos bolsistas Capes/Reuni. Na maioria dos relatos é conferido ao professor tutor o papel da equipe didática:

Minha experiência com o professor tutor foi, de fato, maravilhosa. Muito atencioso, ele me orientou de maneira muito especial, me considerando um parceiro de suas aulas. Atuamos juntos todas as semanas e nos reuníamos sempre em conversas e análises muito generosas. Por outro lado, meu tutor foi um grande exemplo como professor, como orientador e como um performer da educação superior. Essa, contudo, não foi a experiência da maioria dos meus colegas que eram bolsistas Reuni. Uns assumiram disciplinas inteiras, outros tiveram poucas ou nenhuma atribuição. A falta de informação sobre o regime da Bolsa Reuni era generalizada. Nesse sentido, eu tive muita sorte.

Não obstante o programa de adesão da UMFG ao Reuni prever o acompanhamento dos bolsistas, em termos quantitativos, $13 \%$ dos respondentes consideraram que não receberam qualquer tipo de auxílio ou apoio na realização das atividades previstas. Considerando os dados acima expostos, seria de se esperar que os bolsistas não conhecessem, em sua grande maioria, a regulamentação referente à organização das equipes

\footnotetext{
${ }^{7}$ Cursista 259.
} 
didáticas na proposta de adesão ao Reuni. Tal expectativa não se sustentou ao analisarmos os dados. Podemos dizer que mais da metade dos respondentes tinha conhecimento da regulamentação referente às equipes didáticas. Ou seja, tais sujeitos sabiam da necessidade da existência de uma equipe de apoio à sua formação e ainda que essa equipe deveria propor uma série de inovações pedagógicas na universidade, frente ao processo de expansão do ensino.

Ao analisarmos a experiência dos sujeitos que participaram da pesquisa, percebemos que, quando inquiridos sobre a importância de participar de uma equipe didática, $92 \%$ responderam que seria relevante ou muito relevante. Os dados demonstram que, em geral, ter participado de uma equipe que tivesse o objetivo de refletir sobre a prática docente, pensar novas formas do fazer docente, e que, ao mesmo tempo, permitisse a troca de experiências entre docentes em formação e docentes em atuação seria um fator positivo em sua formação. Seguem-se dois relatos que evidenciam os sentidos conferidos pelos bolsistas ao que se refere à importância das equipes didáticas em sua formação:

Constituir uma equipe pedagógica é o primeiro exercício para quem quer mostrar ao aluno que o trabalho em saúde é um trabalho coletivo que exige, inequivocamente, a integração dos profissionais. É preciso mostrar para eles que a integração é possível dentro de uma equipe que de forma articulada conduz atividades diferenciadas e com metodologias mais ativas e reflexivas de ensino. ${ }^{8}$

${ }^{8}$ Cursista 22. 
Sim, à medida que novas situações e problemas são compartilhados pela equipe, você tem de se esforçar para resolver essas questões em conjunto. A troca de experiências e os diversos pontos de vista que incidem sobre essas questões sempre contribuem para o alargamento da consciência sobre o seu papel dentro da prática docente. Isso irradia não apenas à nossa prática profissional, como também à nossa vida pessoal ${ }^{9}$.

Ainda de acordo com os bolsistas, "a experiência com a equipe didática incide no acúmulo de experiência (já citado em outro tópico), o que acredito ser sempre enriquecedor. Lamento não ter atuado em outras atividades, pois tenho certeza que seriam de grande auxílio tanto na vida pessoal, quanto profissional e acadêmica"10 e a participação em uma equipe didática propiciaria a obtenção de maior experiência sobre a área, sobre o sistema interno da universidade. Dessa maneira, favoreceria e aceleraria o aprendizado sobre o cotidiano profissional, proporcionando contanto com demandas e situações que certamente surgirão no decorrer da carreira docente que pretendem seguir.

Nos casos em que houve realmente a efetivação de uma equipe didática, os bolsistas indicam que, em geral, realizaram as seguintes atividades:

- $\quad$ Elaboração de planejamento de aulas;

- Participação na organização de eventos acadêmicos;

\footnotetext{
${ }^{9}$ Cursista 67.

${ }^{10}$ Cursista 58.
} 
- $\quad$ Produção de artigos acadêmicos;

- Debate e discussão sobre a turma em que lecionava;

- Planejamento de disciplina;

- $\quad$ Leitura e discussão de textos;

- Elaboração de avaliação dos discentes.

Sobre as atividades realizadas durante o período em que foram bolsistas Capes/Reuni, há diversos relatos demonstrando características positivas dessa experiência, como pode ser demonstrado através do trecho no qual o cursista considera que a realização das atividades inerentes ao bolsista permitiu "a vivência com alunos da graduação e a evolução da minha didática em sala de aula". ${ }^{11}$ O cursista, que já atuava como professor em duas escolas, avalia que ações combinadas entre professores podem ser mais eficazes na formação dos seus alunos. Assim, ao considerar positiva a experiência de trocas e compartilhamento, apresenta uma postura de construção coletiva do conhecimento considerando-a um fator que auxilia no processo de ensino e aprendizagem. Além disso, argumenta que ao "trocar figurinha" se forma melhor como docente, conhece a realidade da docência previamente, ou lida com os desafios da profissão contando com a ajuda de outros docentes.

\footnotetext{
${ }^{11}$ Cursista 102.
} 
Encontramos também alguns relatos que apresentam aspectos negativos da experiência como bolsista Capes/Reuni. Nesse sentido, a cursista demonstra que, "Infelizmente com a falta de professores, acabei sendo mais uma professora do curso, e não fazendo parte de uma equipe pedagógica. O que aprendi, aprendi na prática com os alunos". ${ }^{12}$ Logo, podemos dizer que a falta de apoio de uma equipe didática ou outro instrumento na formação dessa bolsista pode ter incidido como fator dificultador na realização de suas atividades.

Problemas estruturais também foram apresentados e discutidos pelos bolsistas:

Acho relevante para se pensar a prática em docência. Porém, o que ocorre mesmo é que no Brasil temos uma sobrecarga de atividades para os professores, pesquisadores, coordenadores e discentes que é absurda. Isso sim precisa ser repensado. Uma equipe didática é mais um encargo. Confesso que só pude trabalhar efetivamente em minha pesquisa estando no exterior. Ninguém aqui faz serviço de secretariado ou organização de eventos, serviço técnico ou o que quer que seja. É muito válida a proposta, mas, se o sistema realmente funcionasse a favor dos professores, eles não estariam sobrecarregados, e não estariam sobrecarregando os alunos. E ninguém recebe hora extra por isso. Os alunos trabalham em troca de enriquecimento de currículo. Isso é absurdo. Aqui ninguém emite certificado de curso de nada. Não precisa ficar inchando currículo. Vocês poderiam pesquisar acerca da saúde dos professores universitários e alunos de pós-graduação e sobre trabalho real e prescrito. Seria bem relevante. ${ }^{13}$

\footnotetext{
${ }^{12}$ Cursista 55.

${ }^{13}$ Cursista 140.
} 
Dessa maneira, podemos verificar que, ainda que nem sempre o bolsista tenha contado com a orientação do professor tutor, essa figura se tornou central ou referência na formação da grande maioria dos bolsistas pesquisados.

\section{CONSIDERAÇÕES FINAIS}

Se considerarmos a norma prescrita na proposta de adesão ao Reuni elaborada pela UFMG, a maioria dos pós-graduandos não participou de uma equipe didática. Isso não quer dizer que os bolsistas não tiveram nenhum amparo formativo em suas atividades. Os dados apontam os professores tutores como um dos principais agentes de formação e apoio aos bolsistas. Do total pesquisado, apenas $5 \%$ consideram que fizeram parte de uma equipe didática, enquanto 85 pessoas, ou seja, $57,8 \%$ tiveram a orientação do professor tutor como principal forma de amparo acadêmico.

Essa disparidade deve ser analisada à luz do processo de implantação do Reuni e da organização das equipes didáticas na UFMG. Nos relatos podemos verificar que as equipes didáticas nas faculdades e departamentos da universidade se encontravam em processo de gestação e foram desenvolvidas e implantadas com base na proposta de adesão ao Reuni, mas vislumbrando necessidades específicas.

A falta de orientação no desenvolvimento das atividades como bolsista é considerada negativa. Em alguns casos, o bolsista Capes/Reuni considera que trabalha como um professor efetivo, porém sem receber seus rendimentos. Assim, defendemos que a falta de orientação e apoio pedagógico é 
um fator que nega as diretrizes para a formação do bolsista Capes/Reuni, uma vez que a bolsa deveria garantir a formação de docentes do ensino superior, fortalecendo a articulação entre a pós-graduação e graduação.

De acordo com os próprios cursistas, assumir atividades de docência no ensino superior no momento de sua formação é considerado importante no aprendizado. Contudo, alegam sofrer uma série de pressões para oferecer disciplinas na graduação e, em alguns casos, orientar trabalhos de conclusão de curso, cumprindo ainda suas tarefas na pós-graduação, tais como "cumprir créditos obrigatórios, participar de grupos de pesquisa cadastrados no $\mathrm{CNPq}$, publicar em eventos, publicar artigo, participar de eventos, e, finalmente, escrever a tese". ${ }^{14}$ Assim, podemos concluir que ocorreu uma falta de clareza da importância do suporte pedagógico na formação dos bolsistas Capes/Reuni.

Nos discursos, verificamos a recorrência de vozes conflitantes, que refletem a experiência de cada bolsista Capes/Reuni, experiência essa que variou consideravelmente. Interessante notar que os bolsistas, apesar de terem ingressado em programas de pós-graduação com a intenção de contribuírem para a construção de novos conhecimentos por meio da pesquisa, também consideram positiva a atenção dada à formação de docentes do ensino superior, uma vez que almejam seguir essa carreira.

\footnotetext{
${ }^{14}$ Cursista 95.
} 


\section{REFERÊNCIAS}

BRASIL. Decreto 6.096 de 24 de abril de 2007. Institui o Programa de Apoio a Planos de reestruturação e Apoio e Expansão das Universidades Federais - REUNI. Brasília: MEC, 2007.

BRASIL. Ministério da Educação. REUNI. Reestruturação e Expansão das Universidades Federais: Diretrizes Gerais. Brasília: PDE, 2007. p. 10. Disponível em: <http://portal. mec.gov.br/sesu/arquivos/pdf/diretrizesreuni.pdf $>$. Acesso em: 31 jan. 2014.

COELHO, Maria de Lourdes. Processos de constituição da docência universitária: o Reuni na UFMG. Tese (Doutorado em Educação), Faculdade de Educação, Universidade Federal de Minas Gerais, Belo Horizonte, 2012.

UFMG-REUNI. Universidade Federal de Minas Gerais: REUNI. Disponível em: <http://www.ufmg.br/reuni/>. Acesso em: 31 jan. 2014.

\section{FONTES CONSULTADAS}

Planejamentos das equipes pedagógicas da Universidade Federal de Minas Gerais CAPES/REUNI. Curso de Graduação em Arquivologia - 2011.

Planejamentos das equipes pedagógicas da Universidade Federal de Minas Gerais CAPES/REUNI. Curso de Comunicação Social - 2011.

Planejamentos das equipes pedagógicas da Universidade Federal de Minas Gerais CAPES/REUNI. Curso de Museologia - 2011/2012. 
Planejamentos das equipes pedagógicas da Universidade Federal de Minas Gerais CAPES/REUNI. Curso de Arquitetura e Urbanismo - 2010-2012.

Planejamentos das equipes pedagógicas da Universidade Federal de Minas Gerais CAPES/REUNI. Curso de Bacharelado em Ciências do Estado - 2011.

Planejamentos das equipes pedagógicas da Universidade Federal de Minas Gerais CAPES/REUNI. Curso de Design de Moda - 2011-2012.

Planejamentos das equipes pedagógicas da Universidade Federal de Minas Gerais CAPES/REUNI. Curso Restauração de Bens Culturais Móveis - 2011.

Planejamentos das equipes pedagógicas da Universidade Federal de Minas Gerais CAPES/REUNI. Curso de Filosofia - 2011.

Planejamentos das equipes pedagógicas da Universidade Federal de Minas Gerais CAPES/REUNI. curso de Antropologia - 2011

Planejamentos das equipes pedagógicas da Universidade Federal de Minas Gerais CAPES/REUNI. Equipe de Assistência a Docência de Gestão Pública - 2011.

Planejamentos das equipes pedagógicas da Universidade Federal de Minas Gerais CAPES/REUNI. Equipe de Metodologia do Departamento de Ciência Política - 2011.

Planejamentos das equipes pedagógicas da Universidade Federal de Minas Gerais CAPES/REUNI. Equipe de Docência do Ciclo Introdutório de Ciências Humanas 2011. 
Planejamentos das equipes pedagógicas da Universidade Federal de Minas Gerais CAPES/REUNI. Curso de Ciência Política 2011.

Planejamentos das equipes pedagógicas da Universidade Federal de Minas Gerais CAPES/REUNI. Escola de Música $-2011$

Planejamentos das equipes pedagógicas da Universidade Federal de Minas Gerais CAPES/REUNI. Departamento de Estatística - 2011.

Planejamentos das equipes pedagógicas da Universidade Federal de Minas Gerais CAPES/REUNI. Curso de Matemática - 2011.

Planejamentos das equipes pedagógicas da Universidade Federal de Minas Gerais CAPES/REUNI. Curso de Engenharia Ambiental - 2011.

Planejamentos das equipes pedagógicas da Universidade Federal de Minas Gerais CAPES/REUNI. Curso Engenharia de Sistemas - 2011.

Planejamentos das equipes pedagógicas da Universidade Federal de Minas Gerais CAPES/REUNI. Faculdade de Farmácia-2011.

Planejamentos das equipes pedagógicas da Universidade Federal de Minas Gerais CAPES/REUNI. Curso de Geografia - 2011. 


\section{ABSTRACT}

This article aims to discuss the role of the didactic teams in the training of UFMG master and PhD students who have attended the Undergraduation Teaching Training offered by GIZ - Technological Innovation Board. Furthermore, the goal of this paper is to discuss and relate the role of the tutor lecturer to the graduate students training. For this purpose, we used data collected with the application of a questionnaire to those students.

We conclude that the graduate students who took part in this study, in general, consider taking part in a didactic team important to their training, as it's favourable to the collective construction of knowledge and horizontality in the relationship lecturer/advisor and student. Furthermore, they consider that performing in teaching projects can be taken as a positive training element which anticipates situations that shall occur in their professional trajectory.

Keywords: Didactic teams. Undergraduation expansion. Undergraduate lecturers training. 